\title{
Determination of cry2A genes in Bacillus thuringiensis isolated from southern provinces of Vietnam
}

\author{
Hoang P. T. Truong ${ }^{1 *}$, Ha K. Duong ${ }^{2}$, Linh B. Ton ${ }^{1}$, Don D. Le ${ }^{1}$, \\ Nhung T. H. Tran ${ }^{1}$, Thuy T. Dang ${ }^{1}$, \& Linh N. C. Huynh ${ }^{1}$ \\ ${ }^{1}$ Research Institute for Biotechnology and Environment, Nong Lam University, Ho Chi Minh City, Vietnam \\ ${ }^{2}$ Research Institute for Plant Varieties, Livestock and Aquatic Products, Ho Chi Minh City, Vietnam
}

ARTICLE INFO
Research Paper
Received: December 18, 2017
Revised: September 20, 2018
Accepted: December 14, 2018
Keywords
Bacillus thuringiensis
cry2A gene
Isolates
PCR
*Corresponding author
Truong Phuoc Thien Hoang
Email: hoangtp@hcmuaf.edu.vn

\begin{abstract}
In 27 isolates of Bacillus thuringiensis from southern provinces of Vietnam with ability to produce bipyramidal inclusions, 21 isolates were positive for cry2A-type genes via PCR methods. Analysis of DNA sequences revealed the amplified products belonged to cry2A-type genes of $\mathrm{B}$. thuringiensis with identity above $90 \%$ compared with cry $2 \mathrm{~A}$ sequences published on GenBank sequence database. The identity values of the amplified products of the isolates BT5 and TN7.1 with cry2A group primers were $97 \%$ and $99 \%$, respectively, while the identity of $99 \%$ were observed in the PCR products of TN7.1 with specific primers for partial sequences of cry2A $a$ and cry2Ab. These results may be useful for prediction of insecticidal activity of the $B$. thuringiensis isolates and development of new bioinsecticide produtcs.
\end{abstract}

Cited as: Truong, H. P. T., Duong, H. K., Ton, L. B., Le, D. D., Tran, N. T. H., Dang, T. T., \& Huynh, L. N. C. (2019). Determination of cry2A genes in Bacillus thuringiensis isolated from southern provinces of Vietnam. The Journal of Agriculture and Development 18(1), 109-116. 


\title{
Xác định gen cry2A trong mẫu vi khuẩn Bacillus thuringiensis phân lập tại các tỉnh thành khu vực miền Nam Việt Nam
}

\author{
Trương Phước Thiên Hoàng ${ }^{1 *}$, Dương Kim Hà ${ }^{2}$, Tôn Bảo Linh ${ }^{1}$, Lê Đình Đôn ${ }^{1}$, \\ Trần Thị Hồng Nhung ${ }^{1}$, Đặng Thị Thủy ${ }^{1}$ \& Huỳnh Nguyễn Chí Linh ${ }^{1}$ \\ ${ }^{1}$ Viện Nghiên Cứu Công Nghệ Sinh Học Và Môi Trường, Trường Đại Học Nông Lâm TP. Hồ Chí Minh, \\ TP. Hồ Chí Minh \\ ${ }^{2}$ Trung Tâm Giống Cây Trồng, Vật Nuôi và Thuỷ Sản, TP. Hồ Chí Minh
}

THÔNG TIN BÀI BÁO
Bài báo khoa học
Ngày nhận: 18/12/2017
Ngày chînh sửa: 20/09/2018
Ngày chấp nhận: 14/12/2018
Từ khóa
Bacillus thuringiensis
Dòng phân lập
Gen cry2A
PCR
*Tác giả liên hệ
Trương Phước Thiên Hoàng
Email: hoangtp@hcmuaf.edu.vn

\section{TÓM TẮT}

Trong 27 mẫu phân lập vi khuẩn Bacillus thuringiensis từ một số tỉnh thành phía nam Việt Nam sinh tinh thể hình thoi có 21 mẫu dương tính với nhóm gen cry2A bằng kỹ thuật $\mathrm{PCR}$. Kết quả phân tích trình tự DNA cho thấy các sản phẩm khuếch đại thuộc nhóm gen cry2A của vi khuẩn $B$. thuringiensis và có độ tương đồng trên $90 \%$ với các trình tự gen cry $2 \mathrm{~A}$ được công bố trên cơ sở dữ liệu gen GenBank. Sản phẩm khuếch đại của mẫu BT5 và TN7.1 với cặp primer chung cho nhóm gen $\operatorname{cry} 2 A$ có độ tương đồng lần lượt là 97 và $99 \%$. Sản phẩm $\mathrm{PCR}$ của mẫu TN7.1 với cặp primer chuyên biệt cho gen $c r y 2 A a$ và $c r y 2 A b$ có giá trị tương đồng đạt $99 \%$ với các gen cùng nhóm đã công bố. Kết quả nghiên cứu có thể được sử dụng để dự đoán hoạt tính diệt côn trùng gây hại của các mẫu phân lập $B$. thuringiensis và phát triển các sản phẩm trừ sâu sinh học mới.

\section{1. Đặt Vấn Đề}

Bacillus thuringiensis $(B t)$ là vi khuẩn Gram dương, có khả năng tạo bào tử, mang các gen cry mã hóa các protein tinh thể độc (protein Cry) có hiệu quả phòng trừ đối với nhiều loại sâu bệnh hại trên cây trồng (Schnepf \& ctv., 1998). Trong những năm qua, các nhà khoa học đã có rất nhiều cố gắng để phân lập vi khuẩn này từ nhiều môi trường khác nhau (Baig \& Mehnaz, 2010; Silva \& ctv., 2012; Dagga \& ctv., 2016). Các nhóm nghiên cứu đã tạo được nhiều bộ sưu tập các chủng Bacillus thuringiensis có khả năng phòng trừ nhiều loại côn trùng và sâu hại với các hoạt tính khác nhau. Gen $c r y$ phổ biến nhất ở các dòng $B t$ tự nhiên là các gen thuộc nhóm cry1, tiếp theo là nhóm cry2 (Ben-Dov \& ctv., 1997; Bravo \& ctv., 1998). Gen cry2 thường tồn tại ở các mẫu $B t$ phân lập từ môi trường tự nhiên và đặc biệt ở các mẫu mang gen cry1 (Lone \& ctv., 2017). Các chế phẩm sinh học $B t$ những năm 1990 và cây trồng công nghệ sinh học thường dựa vào các gen phổ biến như cry $1 A a, c r y 1 A b$ và $\operatorname{cry} 1 A c$ (Sauka \& ctv., 2007; Niu \& ctv., 2017). Sự phụ thuộc này đã dẫn đến gia tăng tính kháng độc tố Cry ở các quần thể côn trùng (Bravo \& ctv., 2011; Ali \& ctv., 2017).

Tuy nhiên, nguồn gen $c r y$ trong tự nhiên rất đa dạng và phong phú. Có khoảng 74 lớp protein Cry và các protein độc tố mới đã được xác định; trong đó 70 gen mã hóa protein độc tố đã được tách dòng (Crickmore, 2017). Mỗi chủng Bt chỉ chứa một số nhóm gen cry gây độc với một số loài côn trùng nhất định (Schnepf \& ctv., 1998). Với sự phát triển và ứng dụng rộng rãi của công nghệ gen ngày nay, việc xác định nhanh các gen cry mong muốn, tạo dòng và xác định trình tự gen độc tố là vấn đề rất cần thiết góp phần cải tiến các thuốc trừ sâu sinh học $B t$ hiện có, đảm bảo 
an toàn cho người sử dụng và an toàn trên sản phẩm nông nghiệp. Nghiên cứu thực hiện nhằm xác định sự hiện diện của các gen cry2 ở các mẫu $B t$ phân lập từ đất ở một số tỉnh thành trong nước. Kết quả nghiên cứu sẽ cung cấp thông tin về gen $c r y$ ở các mẫu $B t$ và có thể ứng dụng để nghiên cứu và phát triển các chế phẩm $B t$ mới (minh chứng tài liệu tham khảo phần nầy).

\section{Vật Liệu và Phương Pháp Nghiên Cứu}

\subsection{Chuẩn bị mẫu vi khuẩn}

Các mẫu phân lập vi khuẩn Bacillus thuringiensis $(B t)$ gồm 27 mẫu từ các tỉnh Bến Tre (4 dòng; BT1, BT2, BT5, BT6), Lâm Đồng (6 dòng; LĐ6.1, LĐ9.1, LĐ10.1, LĐ10.2, LĐ12.1, LĐ21.2), Tây Ninh (5 dòng: TN7.1, TN7.6, TN1.2, TN2.2, TN3.1) và Thành phố Hồ Chí Minh (12 dòng; TP6, TP7, TP21, TP22.2, TP23, TP25.1, TP26.2, TP30.1, TP1.1, TP4.2, TP6.4, TP9.2). Vi khuẩn được duy trì trên môi trường thạch $\mathrm{TSA}$ ở $30^{\circ} \mathrm{C}$ và được dùng để ly trích DNA hay quan sát hình thái tế bào.

\subsection{Quan sát đặc điểm vi thể các mẫu phân lập}

Các mẫu phân lập $B t$ sau 48 giờ nuôi được nhuộm Gram, nhuộm bào tử và tinh thể. Tiến hành nhuộm bào tử và tinh thể theo mô tả của Tortora \& ctv. (2004). Sử dụng thuốc nhuộm Malachite Green với tiêu bản được làm nóng bằng hơi nước, sau đó nhuộm bổ sung safranin. Nội bào tử nhuộm màu xanh lục và vách tế bào có màu đỏ hồng. Đối với nhuộm tinh thể, vết bôi vi khuẩn được nhuộm với safranin trong 1 phút, sau đó rửa và hơ nhanh trên ngọn lửa đèn cồn. Tinh thể $B t$ bắt màu đỏ, bào tử tách rời có viền xung quanh màu đỏ.

\subsection{Tách chiết DNA tổng số và khuếch đại trình tự mục tiêu}

DNA tổng số của các mẫu vi khuẩn sau 48 giờ nuôi cấy được thu nhận theo phương pháp của Khojand \& ctv. (2013). Lấy một ít khuẩn lạc cho vào ống $1,5 \mathrm{~mL}$ có chứa $100 \mu \mathrm{L}$ nước khử ion. Tiến hành sốc nhiệt ở $98^{0} \mathrm{C}$ trong vòng 15 phút. Sau đó, ly tâm ở tốc độ 12000 rpm trong 5 phút, thu dịch nổi có chứa DNA sang ống $1,5 \mathrm{~mL}$ mới và bảo quản ở $-20^{\circ} \mathrm{C}$.

Tiến hành khuếch đại các mẫu DNA đã ly trích với các cặp mồi đặc trưng cho nhóm gen cry2 (Bảng 1). Thành phần phản ứng $\mathrm{PCR}$ thể tích $25 \mu \mathrm{L}$ gồm $12,5 \mu \mathrm{L}$ hỗn hợp MyTaq Mix (Bioline), hỗn hợp primer bao gồm $\mathrm{F}$ primer và $\mathrm{R}$ primer ở nồng độ $0,02 \mu \mathrm{M}, 5 \mu \mathrm{L}$ DNA khuôn sau khi ly trích và $6,5 \mu \mathrm{L}$ nước cất khử ion. Mẫu DNA của chủng Bacillus thuringiensis var. kurstaki (Btk) do TS. Boonhiang Promdonkoy (BIOTEC, Thái Lan) cung cấp được sử dụng làm đối chứng dương.

Phản ứng PCR được thiết lập trên máy Thermal Cycler 2720 (Applied Biosystems). Chu trình nhiệt phản ứng $\mathrm{PCR}$ gồm giai đoạn tiền biến tính ở $95^{0} \mathrm{C}$ trong 1 phút; 30 chu kỳ lặp lại, mỗi chu kì bao gồm các giai đoạn: biến tính ở $95^{0} \mathrm{C}$ trong 15 giây, bắt cặp ở $57^{0} \mathrm{C}$ trong 45 giây với nhiệt độ thay đổi tùy cặp primer sử dụng và $72^{\circ} \mathrm{C}$ trong 1 phút cho giai đoạn kéo dài. Sản phẩm $\mathrm{PCR}$ được bảo quản ở $4^{0} \mathrm{C}$ cho đến khi phân tích.

Kết quả $\mathrm{PCR}$ được kiểm tra bằng cách điện di trên gel agarose (Bioline, Anh) 1\% trong dung dịch đệm TBE (Bioline, Anh) 0,5X. Sản phẩm $\mathrm{PCR}(5 \mu \mathrm{L})$ được trộn đều với $1 \mu \mathrm{L}$ chất nhuộm GelRed (TBR, Việt Nam), được bơm vào từng giếng và điện di ở hiệu điện thế 100 Volt trong 35 phút. Sau khi điện di gel agarose sẽ được đọc kết quả dưới tia UV (Multi-Doc It Imaging System UVP).

\subsection{Tinh sạch sản phẩm $\mathrm{PCR}$ và phân tích trình tự DNA}

Dựa vào kết quả phân tích trên gel agarose, chọn đại diện các mẫu cho đúng sản phẩm mục tiêu để tinh sạch bằng Isolate II PCR and Gel Kit (Bioline) theo hướng dẫn của nhà sản xuất. Sản phẩm PCR sau khi tinh sạch được giải trình tự bởi Công ty First Base (Malaysia).

Kết quả giải trình tự DNA sẽ được phân tích dựa trên cơ sở dữ liệu GenBank và công cụ BLASTn (Basic local alignment search tool for nucleotide, ncbi. nlm.nih.gov). Dựa trên thông tin trình tự DNA nhận được cùng với các trình tự gen cry được công bố trên GenBank tiến hành xây dựng cây phát sinh loài bằng phần mềm MEGAX (Kuma \& ctv., 2018).

\section{Kết Quả và Thảo Luận}

\section{1. Đặc điểm vi thể của các mẫu phân lập $B t$}

Các mẫu phân lập $B t$ đã được khẳng định dựa vào một số đặc tính sinh hóa và vi thể thông 


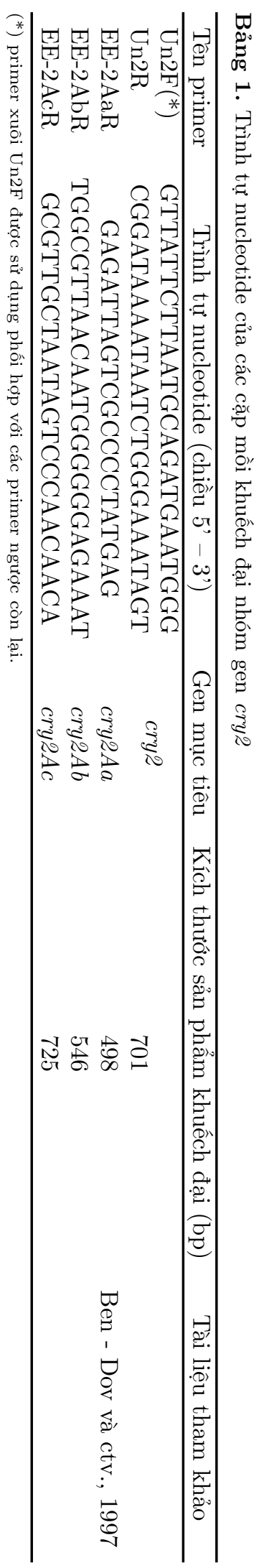

qua nhuộm Gram, hình hình thái tế bào, khả năng sinh tinh thể và bào tử, sử dụng kính hiển vi quang học ở độ phóng đại 100X (vật kính dầu). Dựa vào hình thái tế bào, bào tử và các đặc điểm sinh hóa khó có thể phân biệt được $B$. thuringiensis và các chủng vi khuẩn còn lại trong chi Bacillus. Tuy nhiên, B. thuringiensis có khả năng sinh tinh thể độc trong khi các chủng $B$. subtilis, B. cereus, B. polymyxa, B. mycoides, $B$. licheniformis, B. alvei, B. anthracis, B. coagulans không có khả năng này (Hansen \& Hendriksen, 2001). Tất cả các mẫu phân lập $B t$ đều có tế bào hình que, Gram dương (Hình 1A), có khả năng tạo bào tử và sinh tinh thể (Hình $1 \mathrm{~B}$ ).
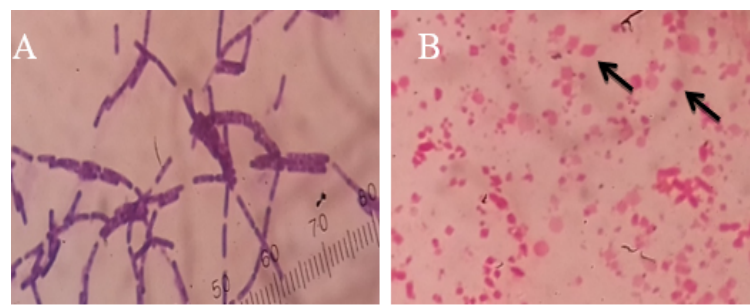

Hình 1. Hình thái tế bào và tinh thể mẫu $B t$ LĐ12.1 dưới kính hiển vi quang học (vật kính 100X). A: vi khuẩn Gram $(+)$, hình que; B:tinh thể hình thoi (mũi tên).

\subsection{Chất lượng dịch chiết DNA}

Kết quả phân tích trên gel điện di ở Hình 2 cho thấy việc sử dụng phương pháp sốc nhiệt để tách chiết DNA và vi khuẩn $B t$ cho kết quả khuếch đại tốt ở mẫu phân lập và đối chứng dượng. Phương pháp trích ly DNA này có một số ưu điểm như quy trình ly trích đơn giản, tiết kiệm hóa chất, thời gian ly trích ngắn và sản phẩm DNA không bị tạp hóa chất ức chế enzyme Taq polymerase như các phương pháp sử dụng phenol. Phương pháp này đặc biệt có lợi cho việc sàng lọc số lượng mẫu $B t$ phân lập từ tự nhiên. Tuy nhiên, mẫu DNA sau khi ly trích theo phương pháp sốc nhiệt bị lẫn tạp protein và RNA.

\subsection{Sự hiện diện của các gen $c r y 2 A$ ở các mẫu $B \dot{t}$}

Kết quả diện di trên gel agarose (Hình 2 và Hình 3) cho thấy 21/27 mẫu phân lập và chủng $B t$ var kurstaki đều tạo ra sản phẩm $\mathrm{PCR}$ duy nhất với kích thước khoảng 701 bp. Jayakumar \& Kaur (2013) cũng có kết quả tương tự khi sử dụng primer Un2 để phát hiện nhóm gen cry2A ở các 


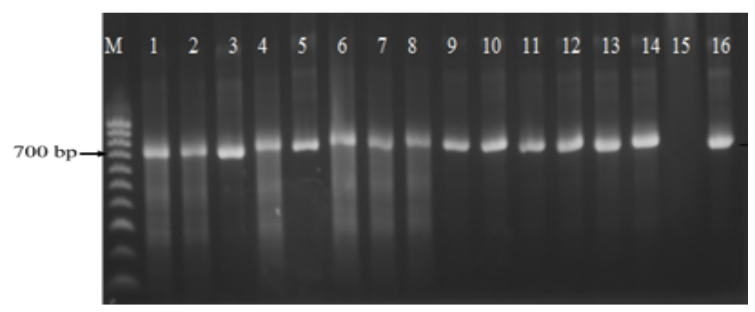

Hình 2. Điện di sản phẩm PCR với cặp mồi Un2 trên gel agarose 1\%, hiệu điện thê 100 Volt. M: thang chuẩn DNA Bioline $100 \mathrm{bp}$, các mẫu phân lập B. thuringiensis (1) LĐ6.1, (2) LĐ9.1, (3) LĐ10.1, (4)LĐ10.2, (5) LĐ12.1, (6) LĐ21.2, (7) TP6, (8) TP7, (9) TP21, (10) TP22.2, (11) TP23, (12) TP25.1, (13) TP26.2, (14) TP30.1, (15) đối chứng âm sử dụng nước cất, (16) đối chứng dương, Bt var kurstaki.

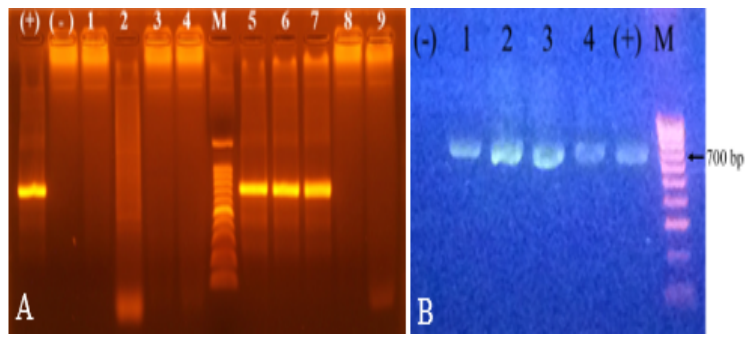

Hình 3. Kết quả điện di sản phẩm $\mathrm{PCR}$ với cặp mồi Un2 trên gel agarose $1 \%$, hiệu điện thế $80 \mathrm{~V}$. (): nước cất, $(+)$ : đối chứng dương $B$. thuringiensis var kurstaki; các mẫu phân lập Bt, (A) 1: TP1.1; 2 : TP4.2; 3: TP6.4; 4: TP9.2; 5: TN7.1; 6: TN7.6; 7: TN1.2; 8: TN2.2; 9: TN3.1; (B) 1: BT1; 2: BT2; 3: BT5; 4: BT6; M: thang chuẩn DNA 100 bp Promega $(\mathrm{A})$ và Bioline $(\mathrm{B})$.

chủng $B t$ phân lập từ tự nhiên. Như vậy 21 mẫu phân lập $B t$ đều có thể mang gen thuộc nhóm cry2A. Bên cạnh đó, kích thước các băng sản phẩm khuếch đại của mẫu $B t$ phân lập hoàn toàn trùng khớp với kích thước sản phẩm khuếch đại của đối chứng dương $B$. thuringiensis var kurstaki và phản ứng đối chứng âm không cho sản phẩm chứng tỏ phản ứng không bị tạp nhiễm. Qua đó có thể kết luận rằng các cặp mồi sử dụng để phát hiện nhóm gen cry2A hoàn toàn đặc hiệu và hoạt động tốt.

Nhiều primer chuyên biệt để phát hiện các phân nhóm cry2A bằng phương pháp $\mathrm{PCR}$ đã được phát triển và sử dụng (Ben-Dov \& ctv., 1997). Kết quả xác định các phân nhóm gen cry2A trên 9 mẫu $B t$ phân lập ở Thành phố Hồ Chí Minh và Tây Ninh cho thấy sự xuất hiện sản phẩm khuếch đại đặc trưng cho gen cry2Aa và $c r y 2 A b$ ở $3 / 9$ mẫu $B t$ gồm TN7.1, TN 7.6 và
TN1.2 (Hình 4). Kích thước mong muốn đối với sản phẩm PCR với cặp mồi đặc hiệu cho phân nhóm gen $c r y 2 A a, c r y 2 A b$ và $c r y 2 A c$ lần lượt là 498 bp, 546 bp và 725 bp (Bảng 1). Sản phẩm khuếch đại vùng gen $c r y 2 A c$ với primer $U n 2 F$ và EE-2AcR của các mẫu phân lập và đối chứng dương (Hình 4) có kích thước khoảng 300 bp 350 bp không đúng với kích thước đã được công bố (725 bp). Theo các tài liệu đã công bố, $B t$ var. kurstaki thường mang gen $c r y 2 A a$ và $c r y 2 A b$ của phân nhóm cry2A (Ben-Dov \& ctv., 1997; Katara \& ctv., 2016). Gen cry2Ac thường hiện diện ở các mẫu phân lập tự nhiên với tần suất thấp và thường đồng xuất hiện với cry2Ab (Ben-Dov \& ctv., 1997; Mendoza \& ctv., 2012) hoặc cry2Aa (Katara \& ctv., 2016). Vì thế sự khác biệt về kích thước ở sản phẩm khuếch đại gen cry2Ac trong nghiên cứu này có thể là sản phẩm không đặc hiệu.
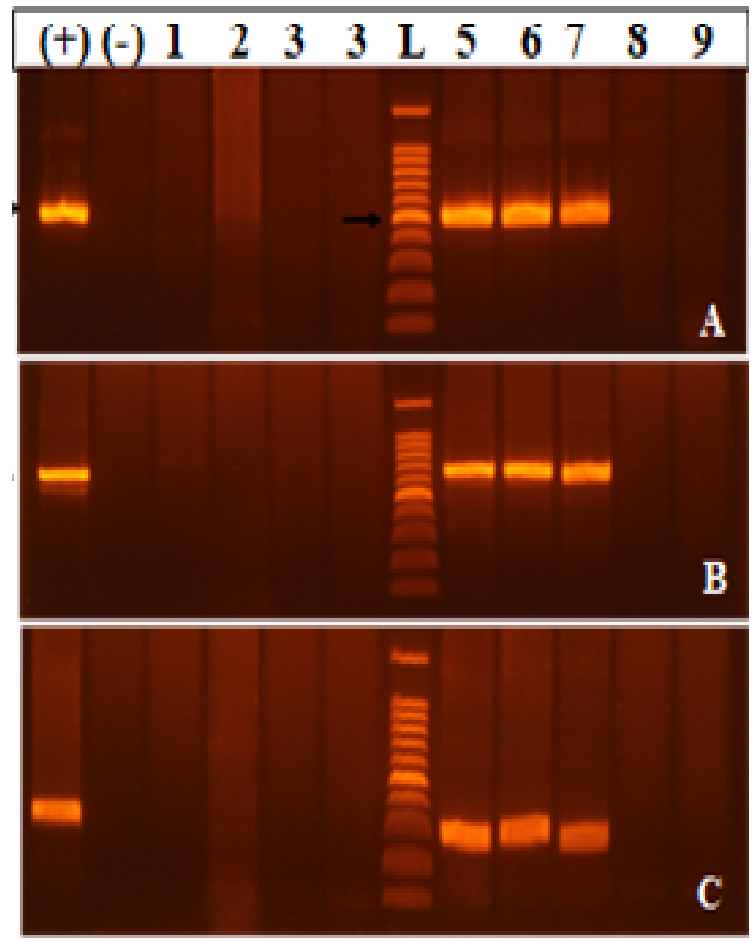

Hình 4. Kết quả điện di trên gel agarose $1 \%$ sản phẩm khuếch đại của các mẫu phân lập $B t$ với cặp mồi đặc hiệu cho gen cry2Aa $(\mathrm{A}), \operatorname{cry2Ab}(\mathrm{B})$ và cry2Ac $(\mathrm{C}) .(+)$ : đối chứng dương $B$. thuringiensis var kurstaki; (-): đối chứng âm, nước cất; các mẫu phân lập Bt, (1) TP1.1; (2) TP4.2; (3) TP6.4; (4) TP9.2; (5) TN7.1; (6) TN7.6; (7) TN1.2; (8) TN2.2; (9) TN3.1; L: thang chuẩn DNA 100 bp (Promega). Mũi tên $=500$ bp. Kích thước sản phẩm PCR mục tiêu như Bảng 1. 


\subsection{Phân tích trình tự sản phẩm $\mathrm{PCR}$}

Để khẳng định kết quả PCR, tiến hành giải trình tự 6 sản phẩm $\mathrm{PCR}$, trong đó gồm 3 sản phẩm khuếch đại với primer Un2 $(\mathrm{Bt} 5-\mathrm{Un} 2$, TN7.1-Un2 và Btk-Un2) và 3 sản phẩm khuếch đại của mẫu TN7.1 với primer chuyên biệt cho gen cry2Aa, cry2Ab và cry2Ac (TN7.1- cry2Aa, TN7.1- cry2Ab, TN7.1- cry2Ac). Mẫu BT5-Un2 được giải trình tự với cả primer $\mathrm{Un} 2 \mathrm{~F}$ và $\mathrm{Un} 2 \mathrm{R}$. Primer Un2F được sử dụng để giải trình tự DNA đối với tất cả các mẫu còn lại. Kết quả giải trình tự được đối chiếu với cơ sở dữ liệu gen của GenBank bằng công cụ BLASTn.

Tất cả các trình tự phân tích đều có độ tương đồng cao (93 - 99\%) với các trình tự gen thuộc nhóm cry2A của Bacillus thuringiensis đã được công bố trên GenBank (Bảng 2). Giá trị tương đồng cao của mẫu đối chứng dương $B t$ var kurstaki $(96 \%)$ cho thấy kết quả giải trình tự đạt chất lượng tốt. Do một số yếu tố ảnh hưởng trong quá trình vận chuyển mẫu và hàm lượng DNA thấp của sản phẩm khuếch đại với primer đặc hiệu gen $c r y 2 A c$ nên trình tự DNA của sản phẩm chưa được xác định.

Kết quả xây dựng cây phát sinh loài dựa trên trình tự khuếch đại các gen thuộc nhóm cry2A của các mẫu phân lập BT5 và TN7.1 cũng cho thấy sự tương đồng cao giữa các trình tự này với trình tự DNA mục tiêu (Hình 5). Trình tự khuếch đại từ mẫu TN7.1 với primer Un2 (TN7.1-cry2A/Un2F) hay Un2/EE2Aa (TN7.1-cry2A/Un2F) được xếp vào cùng nhóm với trình tự gen cry2A (số hiệu GenBank MH475907.1) và cry2Aa (KX24304.1); Trình tự TN7.1-cry2Ab/Un2F được xếp cùng nhóm với gen cry2Ab (KF860847.1). Gen cry2Ac thuộc các nhóm độc lập so với gen $c r y 2 A a$ và $c r y 2 A b$, trong khi $\operatorname{cry} 1 A$ và $\operatorname{cry} 3 A$ là 2 nhóm tách biệt so với các gen thuộc nhóm cry2A. Kết quả nghiên cứu của Liang \& ctv. (2011) cũng cho thấy sự xuất hiện đồng thời ở tần suất cao của gen $c r y 2 A a$ và $c r y 2 A b$ ở các mẫu phân lập $B t$ từ đất có kết quả PCR dương tính với cặp primer chung cho nhóm cry2A.

\section{Kết Luận}

Trong 27 mẫu phân lập vi khuẩn Bacillus thuringiensis từ một số tỉnh thành phía nam Việt Nam có 21 mẫu được xác định dương tính với nhóm gen cry2A bằng kỹ thuật PCR. Kết quả

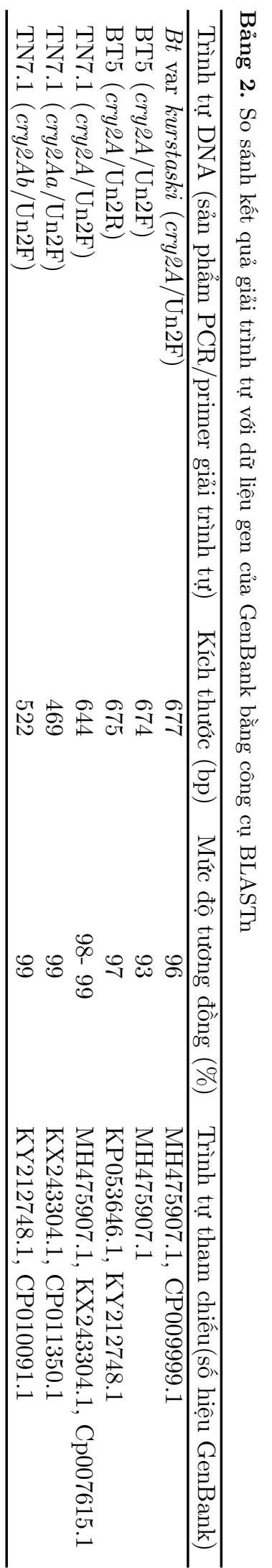




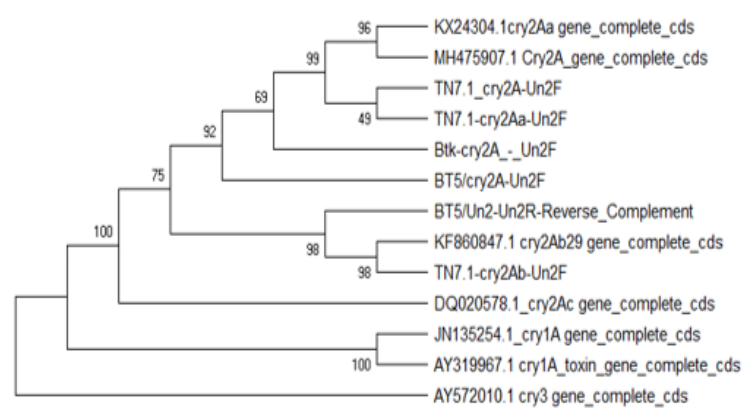

Hình 5. Mối liên hệ giữa các trình tự sản phẩm khuếch đại thuộc nhóm gen $c r y 2 A$ của các mẫu phân lập $B$. thuringiensis và các trình tự gen cry từ cơ sở dữ liệu GenBank. Sơ đồ được xây dựng dựa trên phương pháp Maximum Likelihood và mô hình thông số Kimura 2 với 1000 lần lặp lại (bootstrap $\mathrm{n}=1000$ ). Tỉ lệ lặp lại của các nhóm phân loại được thể hiện ở các nhánh.

phân tích trình tự DNA cho thấy các sản phẩm khuếch đại của các mẫu vi khuẩn $B$. thuringiensis BT5 và TN7.1 thuộc nhóm gen cry2A và có độ tương đồng cao (97\% và $99 \%$ ) với các trình tự gen cry2A được công bố trên cơ sở dữ liệu gen GenBank. Sản phẩm PCR của mẫu TN7.1 với cặp primer chuyên biệt cho gen $c r y 2 A a$ và $c r y 2 A b$ có giá trị tương đồng đạt $99 \%$ với các gen cùng nhóm đã công bố. Sự hiện diện của gen $c r y 2 A c$ trên Btk và các mẫu phân lập cần được khảo sát thêm. Kết quả nghiên cứu đã cung cấp thông tin về nhóm gen $c r y 2 A$ ở các mẫu $B t$ phân lập từ đất ở các tỉnh thành khu vực miền Nam Việt Nam, có thể sử dụng để dự đoán phạm vi diệt côn trùng gây hại của các mẫu phân lập $B t$ và phát triển các chế phẩm $B t$ mới.

\section{Lời Cảm Ơn}

Cảm ơn Sở Khoa học Công nghệ Thành phố Hồ Chí Minh và Bộ Giáo dục và Đào tạo đã hỗ trợ kinh phí thực hiện nghiên cứu.

\section{Tài Liệu Tham Khảo (References)}

Ali, G., van der Werf, W., \& Vlak, J. M. (2017). Biological and genetic characterization of a Pakistani isolate of Spodoptera litura nucleopolyhedrovirus. Biocontrol Science and Technology 28(1), 20-33.

Baig, D. N., \& Mehnaz, S. (2010). Determination and distribution of cry-type genes in halophilc Bacillus thuringiensis isolates of Arabian Sea sedimentary rocks. Microbiological Research 165(5), 376-383.

Ben-Dov, E., Zaritsky, A., Dahan, E., Barak, Z., Sinai,
R., Manasherob, R., Khamraev, A., Troitskaya, E., Dubitsky, A., Berezina, N., \& Margalith, Y. (1997). Extended screening by PCR for seven cry group genes from field-collected strains of Bacillus thuringiensis. Applied and Environmental Microbiology 63, 48834890.

Bravo, A., Likitvivatanavong, S., Gill, S. S., \& Soberón, M. (2011). Bacillus thuringiensis: A story of a successful bioinsecticide. Insect Biochemistry and Molecular Biology 41(7), 423-431.

Bravo, A., Sarabia, S., Lopez, L., Ontiveros, H., Abarca, C., Ortiz, A., \& Quintero, R. (1998). Characterization of cry genes in a Mexican Bacillus thuringiensis strain collection. Applied and Environmental Microbiology 64(12), 4965-4972.

Crickmore, N. (2017). Bacillus thuringiensis toxin classification. In Fiuza, L. M., Polanczyk, R. A., \& Crickmore, N. (Eds.). Bacillus thuringiensis and Lysinibacillus Lysinibacillus sphaericus: Characterization and use in the field of biocontrol (41-52). Cham, Switzerland: Springer International Publishing.

Dagga, A. A. M., Amnama, A. A. A., Al-Sharif, M., \& Hindi, M. E. (2016). Isolation and molecular characterization of cry gene for Bacillus thuringiensis isolated from soil of Gaza strip. International Journal of Current Microbiology and Applied Sciences 5(4), 659-666.

Hansen, B. M., \& Hendriksen, N. B. (2001) Detection of enterotoxic Bacillus Cereus and Bacillus Thuringiensis strains by PCR analysis. Applied and environmental Microbiology 67(1), 185-189.

Jayakumar, S., \& Kaur, S. (2013). Occurrence of cry genes in Bacillus thuringiensis (Bt) isolates recovered from phylloplanes of crops growing in the New Delhi region of India and toxicity towards Diamondback moth (Plutella xylostella). Journal of Biological Sciences 13, 463-473.

Katara, J. L., Kaur, S., Kumari, G. K., \& Singh, N. K. (2016). Prevalence of cry2-type genes in Bacillus thuringiensis isolates recovered from diverse habitats in India and isolation of a novel cry2Af2 gene toxic to Helicoverpa armigera (cotton boll worm). Canadian Journal of Microbiology 62(12), 1003-1012.

Khojand, S., Keshavarzi, M., Zagargi, K., Abdolahi, H., \& Rouzbeh, F. (2013). Presence of multiple cry genes in Bacillus thuringiensis isolated from dead cotton bollworm Heliothis armigera. Journal of Agricultural Science and Technology 15, 1285-1292.

Kumar, S., Stecher, G., Li, M., Knyaz, C., \& Tamura K. (2018). MEGA X: Molecular evolutionary genetics analysis across computing platforms. Molecular Biology and Evolution 35, 1547-1549.

Liang, H., Liu, Y., Zhu, J., Peng, G., Li, S., Wang, S., \& Li, P. (2011). Characterization of cry2-type genes of Bacillus thuringiensis strains from soilisolated of Sichuan basin, China. Brazilian Journal of Microbiology 42(1), 140-146. 
Lone, S. A., Malik, A., \& Padaria, J. C. (2017) Characterization of lepidopteran-specific cry1 and cry2 gene harbouring native Bacillus thuringiensis isolates toxic against Helicoverpa armigera. Biotechnology Reports $15,27-32$.

Mendoza, G., Portillo, A., Arias, E., Ribas, R. M., \& Olmos, J. (2012). New combinations of cry genes from Bacillus thuringiensis strains isolated from northwestern Mexico. International Microbiology 15, 209-216.

Niu, L., Mannakkara, A., Qiu, L., Wang, X., Hua, H., Lei, C., \& Ma, W. (2017). Transgenic Bt rice lines producing $C r y 1 A c, C r y 2 A a$ or $C r y 1 C a$ have no detrimental effects on brown planthopper and pond wolf spider. Scientific Reports, 7(1), 1940-1940.

Sauka, D. H., Amadio, A. F, Zandomeni, R. O., \& Benintende, G. B. (2007). Strategy for amplification and sequencing of insecticidal cry $1 A$ genes from Bacillus thuringiensis. Antonie van Leeuwenhoek 91(4), 423-430.
Silva, M. C., Siqueira, H. A. A., Marques, E. J., Silva, L. M., Barros, R., Lima Filho, J. V. M., \& Silva, S. M. F. A. (2012). Bacillus thuringiensis isolates from northeastern Brazil and their activities against Plutella xylostella (Lepidoptera: Plutellidae) and Spodoptera frugiperda (Lepidoptera: Noctuidae). Biocontrol Science and Technology 22(5), 583-599.

Schnepf, E., Crickmore, N., Van Rie, J., Lereclus, D., Baum, J., Feitelson, J., Zeigler, D. R., \& Dean, D. H. (1998). Bacillus thuringiensis and its pesticidal crystal proteins. Microbiology and Molecular Biology Reviews 62(3), 775-806.

Tortora, G. J., Funke, B. R., \& Case, C. L. (Eds.) (2004). Microbiology - An introduction ( $8^{\text {th }}$ ed.). San Francisco, CA, USA: Pearson Benjamin Cummings. 